\title{
Memories of Elias M. Stein
}

\author{
Steven G. Krantz ${ }^{1}$
}

Accepted: 7 January 2021 / Published online: 24 March 2021

(c) Mathematica Josephina, Inc. 2021

Elias M. Stein was a great and influential mathematician and also a fine human being. He directed more than $50 \mathrm{Ph} . \mathrm{D}$. students, many of whom went on to become prominent mathematicians in their own right. He wrote quite a number of influential books and more than 200 papers.

Stein was my teacher and my friend, and he had an enormous influence on my life and my career. I know that hundreds of other mathematicians can say something similar about their own lives.

Stein was expert in all parts of harmonic analysis. He made important contributions to singular integrals, to Hardy spaces, to Lie theory, to several complex variables, and to many other parts of the subject. His teaching was superb, and he exerted a tremendous influence around the world. He had 552 mathematical descendants and thousands of followers.

Stein's papers were of course seminal. But his books have had a profound and long-range influence. His book on singular integrals is one of the best-selling monographs of all time. His book with Guido Weiss on Fourier analysis is exemplary. And his tome "Harmonic Analysis" is a pillar of wisdom.

Eli Stein will be remembered warmly and for a long time. His effect has been tremendous, and will be felt for generations.

Publisher's Note Springer Nature remains neutral with regard to jurisdictional claims in published maps and institutional affiliations.

Steven G. Krantz

sk@math.wustl.edu

1 Washington University in St. Louis, St. Louis, MO, USA 